\title{
AÇÚCAR MASCAVO E ENSINO DE CIÊNCIAS: UMA PROPOSTA INTERDISCIPLINAR
}

Maria Josielma de Queiroz Silva* (Graduanda em Química na Universidade Federal de Campina Grande UFCG/CES);

Pedro Maxuel Paulino Cabral (Graduando em Química na Universidade Federal de Campina Grande UFCG/CES);

Evandro Rogério da Silva (Graduando em Química na Universidade Federal de Campina Grande - UFCG/CES); Marielle Rosane Soares dos Santos (Graduanda em Química na Universidade Federal de Campina Grande UFCG/CES);

José Carlos de Freitas Paula (Prof. Adj. da UABQ na Universidade Federal de Campina Grande - UFCG/CES);

*Email: josielma_queiroz@hotmail.com

\section{Resumo:}

O estado da Paraíba possui um importante papel na formação da cultura e riqueza do povo brasileiro remontando ao período colonial com a construção dos engenhos de cana de açúcar na zona da mata e brejo paraibanos. Esta visão sobre nossa história fornece possibilidades de exploração do conteúdo de diferentes áreas do conhecimento. Uma abordagem adequada possibilita desenvolver uma estratégia interdisciplinar de ensino ou mesmo multidisciplinar. Um dos primeiros produtos obtidos da cana de açúcar depois do mel é o açúcar mascavo, um produto mais rico nutricionalmente que o açúcar refinado.

Nosso objetivo é desenvolver o tema numa turma do ensino médio em vista da compreensão de como o conhecimento científico e tecnológico influenciou as relações sociais no Brasil colônia, comparar o modo de produção para diferentes tipos de açúcar (mascavo, demerara e cristal), compreender como a revolução industrial influenciou a produção e a vida nos engenhos do século XVII, por que a cana é a matéria prima na produção de açúcar em nosso país, etc. A metodologia aplicada nesse trabalho iniciou com a filtração e cozimento do caldo obtido na ferira livre da cidade de Cuité. Evaporamos e cozinhamos o caldo até a retirada de pelo menos $75 \%$ da água e transformá-lo em um xarope concentrado. Com o cozimento produzimos uma pasta densa que ao ser resfriada foi macerada para dar origem ao açúcar mascavo. Nesse processo não temos a cristalização pois seria necessário o emprego de uma centrífuga. Na primeira etapa tivemos êxito com a obtenção do açúcar e estamos planejando juntos com professores da educação básica, numa escola pública de Cuité/PB, as sequencias didáticas além da escolha do público alvo para a vivência da segunda etapa do projeto. Identificamos na área de química alguns conteúdos que podem ser desenvolvidos entorno tema como separação de misturas (destilação simples, destilação fracionada e cristalização), fermentação (produção de álcool e cachaça); em história, capitanias hereditárias, mão de obra escrava e o modo de produção capitalista, o papel da tecnologia para produção de açúcar; em biologia, biotecnologia com o papel dos microorganismos no processo de fermentação e em geografia a importância do clima e do relevo para a produção da cana-de-açúcar, etc.

Concluímos que o tema é uma boa opção de tema gerador para o ensino de química e ciências, além de permitir a contribuição de outras áreas do conhecimento na construção de uma compreensão mais ampla do processo de obtenção de um produto muito presente às mesas dos próprios alunos e que possui um referencial histórico e geográfico numa região vizinha ao Curimataú, o brejo paraibano.

\section{Palavras-chave:}

Açúcar mascavo; Interdisciplinaridade; Ensino-aprendizagem. 
Espaço reservado para organização do congresso. 


\section{Introdução}

A cana-de-açúcar teve sua origem na Nova Guiné, onde sua existência era tida como planta ornamental. Não se sabe como a planta silvestre da Nova Guiné torna-se matéria prima para produção de açúcar. A "domesticação" da cana na Nova Guiné teria sido realizada cerca de 8.000 anos antes de Cristo por horticultores neolíticos. O fato é que a cana, que pertence à da família das gramíneas fez um percurso por várias linhas do pacífico sul passando pela Malásia e Bengala até chegar à Índia, quando por volta do ano 327 a. C. os escribas de Alexandre "o grande" anotaram que os nativos "mascavam uma cana maravilhosa, que produzia uma espécie de "mel' sem ajuda das abelhas" (FILHO, 2009). Da Pérsia, a cana foi levada pelos árabes para a Espanha, Sicília, Marrocos, Egito e outras regiões mediterrâneas. No século XV, os portugueses e os espanhóis a introduziram na Ilha da Madeira, Canárias, Cabo Verde e São Tomé, e na África Ocidental (BAYMA, 1974).

Na América, as primeiras mudas foram trazidas por Cristóvão Colombo por ocasião de sua segunda viagem, e plantadas primeiramente em Santo Domingo. A cana-de-açúcar chega ao Brasil no início do século XVI, trazida pelos portugueses para a capitania hereditária de Itamaracá que incluía terras que hoje pertencem a Paraíba (SILVA, 2010). Dentro desse contexto o estado da Paraíba possui um importante papel na formação da cultura e riqueza do povo brasileiro com a construção dos engenhos de cana de açúcar na zona da mata e brejo paraibanos. Esta visão sobre nossa história fornece possibilidades de exploração do conteúdo de diferentes áreas do conhecimento.

A cana de açúcar está presente na vida de todos os brasileiros estejam na zona da mata ou no sertão, em contato com plantios para produção de açúcar e álcool ou rapadura, ou para alimentar o gado ou até mesmo para o simples consumo na forma de caldo. $\mathrm{O}$ fato é que temos um produto muito comum mas pouco conhecido por nós mesmos e por nossos alunos. Ter conhecimento deste percurso histórico, incluindo aí aspectos sociais e tecnológicos para a cana e sua finalidade é parte importante para a construção de uma compreensão crítica sobre o tema. E neste sentido os documentos oficiais apontam para a necessidade de transformação do ensino médio:

Uma formação com tal ambição exige métodos de aprendizado compatíveis, ou seja, condições efetivas para que os alunos possam: - comunicar-se e argumentar; • defrontar-se com problemas, compreendê-los e enfrentá-los; • participar de um convívio social que lhes dê oportunidades de se realizarem como cidadãos; • fazer escolhas e proposições; • tomar gosto pelo conhecimento, aprender a aprender $(\mathrm{PCN}+$, 2006).

Essa transformação parte do pressuposto que o ensino médio é etapa conclusiva da educação básica de toda a população estudantil - e não mais somente uma preparação para outra etapa escolar ou para o exercício profissional. Isso desafia a comunidade educacional a pôr em prática propostas que superem as limitações do antigo ensino médio. A estratégia proposta baseia-se no ensino por projeto que entre outras vantagens possibilita o protagonismo do aluno na construção do seu próprio saber. Segundo Cachapuz (2002) a perspectiva de Ensino por Projeto em Ciências, em termos de finalidade, deixa de se preocupar somente com a aprendizagem de um corpo de conhecimentos ou processos da ciência, mas antes de garantir que tais aprendizagens se tornarão úteis e utilizáveis no cotidiano - não numa perspectiva meramente instrumental mas, sim numa perspectiva de ação - no sentido de contribuírem para o desenvolvimento pessoal e social dos alunos. Dessa forma é cada vez maior o apelo à inter e transdisciplinaridade, decorrente da necessidade de compreender o mundo na sua totalidade. Nogueira (2012) aponta para a necessidade de concebermos o conhecimento como cadeia de significados evitando assim uma estrutura de pré-requisitos e hierarquização dos mesmos numa estrutura linear. O conhecimento forma uma espécie de rede com múltiplas interligações, formando uma malha entre os significados e suas relações, que no caso desse tema podemos refletir com os alunos sobre as mudanças de tecnologias na extração do caldo de cana que inicialmente era feitas por tração humana, depois por tração animal, em seguida por máquinas a vapor e por último por máquinas a diesel. Essas evoluções trazem consequências para as relações sociais nos engenhos; a revolução industrial impacta a produtividade e até nas leis que libertam escravos.

\section{Objetivo}


O objetivo deste trabalho é desenvolver uma estratégia de ensino que permita uma abordagem interdisciplinar do tema proposto, baseada na perspectiva de ensino por projeto.

\section{Metodologia}

Inicialmente realizamos experimentos para a obtenção de açúcar mascavo no Laboratório de Pesquisa no Ensino de Química (LaPEQ) da Universidade Federal de Campina Grande, Centro de educação e Saúde (UFCG/CES). Foi feita a filtração do caldo para que fossem removidas as impurezas contidas no caldo obtido na feira livre da cidade de Cuité. Após a filtração do caldo iniciamos o aquecimento e cozimento do caldo de cana com a utilização de uma chapa de aquecimento a uma temperatura de $130^{\circ} \mathrm{C}$. A série de experimentos considerou inicialmente uma redução gradual no volume de água a partir de $50 \%$ a $90 \%$ mantendo o $\mathrm{pH}$ constante. Notamos que a textura própria para uma rapadura mole, que dá origem ao açúcar, ocorreu com uma redução de $75 \%$ do volume da solução com a adição de $5 \mathrm{~g}$ de cal hidratada a um litro de caldo. Após evaporarmos e cozinharmos o caldo até o ponto desejado produzimos uma pasta densa que ao ser resfriada foi macerada para dar origem ao açúcar mascavo. Realizamos um primeiro encontro com a equipe de professores da escola Aguitônio Dantas em Frei Martinho na região do Curimataú paraibano para discutirmos o planejamento da atividade. A reunião não foi conclusiva, ficando os professores e a equipe pedagógica com o compromisso de escolher a turma de alunos do ensino médio que fará parte dessa atividade. As imagens I e II mostram parte do processo de fabricação do açúcar em laboratório. A partir deste experimento percebemos que um recipiente com formato circular facilita a agitação da mistura proporcionando a obtenção de cristais de açúcar. Nossa intensão é trazer os alunos da escola para realizar alguns experimentos em nosso laboratório e incentivar a realização e práticas na própria escola com material de baixo custo.

Imagens I e II - caldo de cana em ebulição.
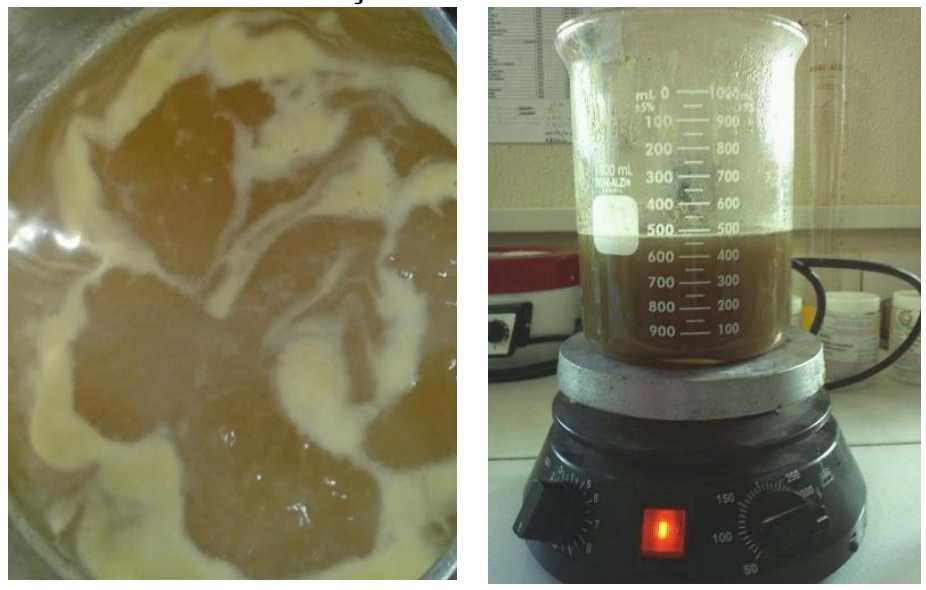

O Quadro I apresenta algumas das relações entre as atividades propostas com as competências apresentadas nas Orientações Curriculares Nacionais para o Ensino Médio em química. As atividades são propostas visando alcançar a construção de tais competências considerando a possibilidade de outras atividades contribuírem para a construção de uma mesma competência ou criarmos outras atividades complementares.

Quadro I - Previsão de atividades com respectivas competências a serem desenvolvidas em química.

\begin{tabular}{|c|c|}
\hline Atividade (s) proposta(s) & Competência \\
\hline $\begin{array}{l}\text { - Leitura de rótulos de embalagens de } \\
\text { açúcar; ler tabelas com informações } \\
\text { nutricionais do açúcar mascavo e } \\
\text { comparar com outras composições do } \\
\text { produto (Mg, Fe, Calorias, Zn, \% VD, g, } \\
\text { mg, etc.); }\end{array}$ & $\begin{array}{l}\text { - Reconhecer e compreender símbolos, códigos } \\
\text { e nomenclatura própria da Química e da tecnologia } \\
\text { química; } \\
\text { - Identificar e relacionar unidades de medida } \\
\text { usadas para diferentes grandezas, como massa, energia, } \\
\text { tempo, volume, densidade, concentração de soluções. }\end{array}$ \\
\hline - Pesquisar e discutir sobre os produtos & Analisar e interpretar diferentes tipos de textos \\
\hline
\end{tabular}




\begin{tabular}{|c|c|}
\hline $\begin{array}{l}\text { obtidos a partir da cana (açúcar, álcool, } \\
\text { vinagre, celulose, etc.) e as diferentes } \\
\text { tecnologias empregadas ao longo do } \\
\text { tempo; } \\
\text { - Pesquisar e discutir sobre biocombustíveis } \\
\text { utilizando livros, internet, etc. } \\
\text { - Visitar o engenho Triunfo e o engenho } \\
\text { Bujari ambos em Areia/PB; visitar a usina } \\
\text { Monte Alegre em Mamanguape, etc. }\end{array}$ & $\begin{array}{l}\text { e comunicações referentes ao conhecimento científico } \\
\text { e tecnológico químico; } \\
\text { - Consultar e pesquisar diferentes fontes de } \\
\text { informação, como enciclopédias, textos didáticos, } \\
\text { manuais, teses, internet, entrevistas a técnicos e } \\
\text { especialistas. }\end{array}$ \\
\hline $\begin{array}{l}\text { - Discutir a ideia entorno do significado de } \\
\text { "produto natural" para o açúcar mascavo } \\
\text { se comparado ao açúcar demerara e ao } \\
\text { açúcar cristal; } \\
\text { Elaborar relatórios das visitas às } \\
\text { industrias químicas, informando sobre } \\
\text { seus processos; elaborar relatório de } \\
\text { experimentos de fabricação de açúcar } \\
\text { mascavo e etanol, descrevendo materiais, } \\
\text { procedimentos e conclusões; }\end{array}$ & $\begin{array}{l}\text { - Descrever fenômenos, substâncias, materiais, } \\
\text { propriedades e eventos químicos, em linguagem } \\
\text { científica, relacionando-os a descrições na linguagem } \\
\text { corrente } \\
\text { - Elaborar e sistematizar comunicações } \\
\text { descritivas e analíticas pertinentes a eventos químicos, } \\
\text { utilizando linguagem científica, por exemplo, }\end{array}$ \\
\hline $\begin{array}{l}\text { - Estudar as representações químicas para a } \\
\text { composição da sacarose, o que são é } \\
\text { glicídeos, dissacarídeos, ligação peptídica, } \\
\text { etc. } \\
\text { - Realizar experimentos com diferentes pH } \\
\text { para observar a influência deste fator na } \\
\text { formação de cristais de açúcar, etc. }\end{array}$ & $\begin{array}{l}\text { - Reconhecer e compreender fenômenos } \\
\text { envolvendo interações e transformações químicas, } \\
\text { identificando regularidades e invariantes } \\
\text { - } \quad \text { Compreender que as interações entre matéria e } \\
\text { energia, em um certo tempo, resultam em modificações } \\
\text { da forma ou natureza da matéria, considerando os } \\
\text { aspectos qualitativos e macroscópicos; } \\
\text { - Identificar transformações químicas pela } \\
\text { percepção de mudanças na natureza dos materiais ou } \\
\text { da energia, associando-as a uma dada escala de tempo. }\end{array}$ \\
\hline $\begin{array}{l}\text { - Pesquisar e debate sobre a história do } \\
\text { açúcar, a cultura da rapadura na região } \\
\text { nordeste, suas causas e os riscos ao direito } \\
\text { do consumidor. } \\
\text { - Visitar o Museu da rapadura em Areia/PB, } \\
\text { onde encontramos diferentes matrizes } \\
\text { energéticas utilizadas no funcionamento } \\
\text { das moendas. }\end{array}$ & $\begin{array}{l}\text { - Reconhecer e compreender a ciência e tecnologia } \\
\text { químicas como criação humana, portanto inseridas na } \\
\text { história e na sociedade em diferentes épocas; } \\
\text { - Perceber o papel desempenhado pela Química no } \\
\text { desenvolvimento tecnológico e a complexa relação } \\
\text { entre ciência e tecnologia ao longo da história; }\end{array}$ \\
\hline
\end{tabular}

\section{Resultados e discussões}

Com o cozimento obtivemos uma pasta densa de cor marrom-amarelada que é peneirada para obtenção do açúcar mascavo. Na primeira etapa tivemos êxito com a obtenção do açúcar e estamos planejando juntos com professores da educação básica as sequências didáticas para a vivência da segunda etapa do projeto. Ao analisar os resultados, podemos perceber uma grande concentração de glicose e sacarose e sabor marcante, muito semelhante ao da rapadura. Estamos identificando com os professores de outras áreas como história, biologia e geografia as atividades que podem ser desenvolvidas ou como as propostas no quadro I podem ser conduzidas para alcançar competências e habilidades previstas para estas componentes curriculares.

Imagem1 e 2: caldo de cana desidratado 

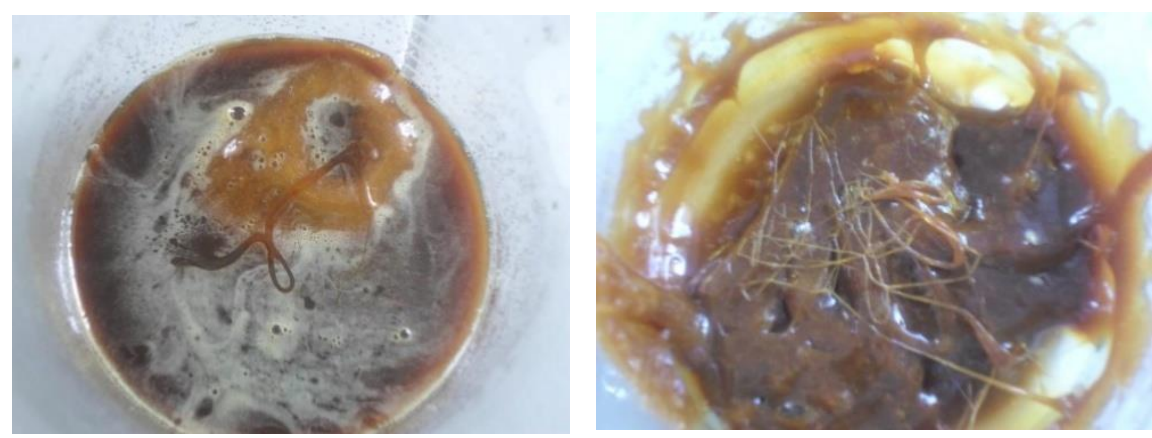

\section{Conclusão}

Concluímos que o tema possibilita uma abordagem interdisciplinar permitindo a contribuição de outras áreas do conhecimento na construção de uma compreensão mais ampla do processo de obtenção de um produto muito presente às mesas dos próprios alunos além de contribuir para a formação do senso crítico uma vez que já se houve falar em fraude na produção da rapadura da merenda escolar. Essa é sem dúvida uma das contribuições inerentes a escola para a formação do cidadão, dar condições, a partir do conhecimento científico, para que o aluno goze plenamente dos seus direitos civis e políticos para com o estado e tenha consciência dos seus deveres para com a sociedade.

\section{Brown sugar and teaching of science: an interdisciplinary approach}

\section{Abstract:}

The state of Paraíba has an important role in shaping the culture and richness of the Brazilian people dating from the colonial period with the construction of the sugar cane plantations in the area of forest and swamp Paraíba. This view of our history provides exploration of possibilities content from different fields of knowledge. An appropriate approach makes it possible to develop an interdisciplinary teaching strategy or even multidisciplinary. One of the first products produced from sugar cane after the honey is brown sugar, a richer product nutritionally than refined sugar. We aim to develop the theme in a high school class in view of the understanding of how scientific and technological knowledge has influenced social relations in colonial Brazil, comparing the mode of production for different types of sugar (brown sugar, demerara and crystal), understanding how industrial revolution influenced the production and life in seventeenth-century mills, why sugarcane is a raw material for sugar production in our country, etc. The methodology used in this work began with the filtration and cooking broth obtained in free smitten City Cuité. Evaporated and cook the broth until the removal of at least $75 \%$ of the water and turn it into a concentrated syrup. After cooking produce a thick paste that was macerated to be cooled to give brown sugar. In the process we do not have the crystallization because the use of a centrifuge would be required. In the first stage we were successful with getting the sugar and we are planning together with teachers of basic education in a public school Cuite / PB, the didactic sequences addition to the choice of the target audience to the experience of the second stage of the project. We identified in the chemical area some content that can be developed around theme as separation of mixtures 
(simple distillation, fractional distillation and crystallization), fermentation (alcohol and rum production); in history, captaincies, slave labor and the capitalist mode of production, the role of technology for the production of sugar; in biology, biotechnology with the role of microorganisms in the fermentation process and the importance of geography and climate of the relief for the production of sugarcane, etc. We conclude that the issue is a good generator theme option for teaching chemistry and science, and allows the contribution of other areas of knowledge in building a broader understanding of the process of getting a lot this product to the tables of the students themselves and has a historical and geographical reference in a neighboring region to Curimataú, the Paraiba swamp.

\section{Keywords:}

Brown sugar; interdisciplinarity; teaching and learning

\section{Referências bibliográficas}

FILHO, J. R. A. L.; Desenvolvimento da cana-de-açúcar (Saccharum pp.) sob diferentes formas de colheita e de manejo do palhiço. Piracicaba, 2009. 111p. Tese de Doutorado - Escola Superior de Agricultura "Luiz de Queiroz" - Universidade de São Paulo.

BAYMA, C. Tecnologia do açúcar: da matéria-prima à evaporação. Rio de Janeiro: Instituto do Açúcar e do Álcool, 1974. 292 p. (Coleção Canavieira, 13). Apud FILHO, J. R. A. L.; Desenvolvimento da cana-de-açúcar (Saccharum pp.) sob diferentes formas de colheita e de manejo do palhiço. Piracicaba, 2009. 111p. Tese de Doutorado - Escola Superior de Agricultura "Luiz de Queiroz" Universidade de São Paulo.

SILVA, R.O. Cana de Mel, Sabor de Fel - Capitania de Pernambuco: Uma Intervenção

Pedagógica com Caráter Multi e Interdisciplinar. Química Nova na Escola, vol. 32, n 2, maio de 2010.

BRASIL, MEC, SEB. Orientações Curriculares para o Ensino Médio. Ciências da Natureza, Matemática e suas Tecnologias. Brasília: MEC, SEB, 2006.

CACHAPUZ, A.; PRAIA, J. J. F. M; JORGE, M. P. Ciência, Educação em Ciência e Ensino das Ciências. Ministério da Educação, $1^{\text {a }}$ edição. Lisboa, 2002.

NOGUEIRA, N. R. Pedagogia dos projetos: etapas, papéis e atores, Ed. Érica, $4^{a}$ edição, São Paulo: 2012. 